\title{
User-friendly Instructional Design Tool to Facilitate Course Planning
}

\author{
Agustín Francesa-Alfaro*, Pedro Leiva-Chinchilla ${ }^{\dagger}$, Mario Chacón-Rivas ${ }^{\ddagger}$ y César Garita ${ }^{\S}$ \\ TEC Digital, Instituto Tecnologico de Costa Rica \\ Cartago, Costa Rica \\ Email: $\left\{{ }^{*}\right.$ afrancesa,${ }^{\dagger}$ peleiva, ${ }^{\ddagger}$ machacon, ${ }^{\S}$ cesar\} @tec.ac.cr
}

\begin{abstract}
Plan and take into account the whole picture of the course before it starts, must be a prerequisite for the instructors. At the Tecnológico de Costa Rica, a problem related to course planning has been identified; it is the low detail of the courses planing, associated with the relation between the content and the competences, evaluations and learning objectives, there is not a logical flow on the courses planning. Also the tools used by instructors are not well integrated with their LMS (Learning Management System), which turns the course planning task difficult to track and reinforce. In this context, a web-based application called Instructional Design Tool has been created with the goal to aid instructors in the course planning task, making easier and guided this process by intuitive and usable tool integrated into an LMS, and based on the instructional design theories. To validate our approach, we applied System Usability Scale and eye-tracking tests. The results were interesting, inasmuch they shown the utility of the tool and some improvement points to do.
\end{abstract}

Keywords-e-Learning, Instructional Design, Software, $\operatorname{dotLRN}$, Usability

\section{Introduction}

The problems related with this paper are: many instructors do not use a specific course planning tool; they probably do not follow a well-defined process for course design; they may have not been properly trained in instructional design techniques; and in some cases, they may have just received an old course template that has been modified over time with no detailed course planning. Also, some tools used by instructors are not well integrated with their LMS (Learning Management System), which turns the course planning task very difficult to track and reinforce. All these problems were revealed by a survey conducted at Tecnológico de Costa Rica (TEC) [1].

Therefore, an Instructional Design Tool (ID Tool) has been created with the goal to aid instructors in the course planning task, making easier and guided this process by intuitive and usable tool integrated into an LMS, and based on the instructional design theories.

According to that, the ID Tool provides to the instructors a clear view of the specific steps that they need to follow in order to produce a good and useful design of their courses. This tool is based on the instructional design model created at TEC [2], wich it is based on a session planning where each session encompasses a title, learning objectives, content module, learning activities, means and materials to be used and finally, the learning evaluations. This provides a clear course design, since the instructor can associate all those features in a logical and organized sequence for each session.

Furthermore, this tool was developed with specific usability and visual design criteria to make it more natural, flexible and comfortable to use by instructors. Some additional user-friendly features offered by this tool are: step by step instructions, tooltips, spreadsheet (CSV), general examples and guides for instructors to assist them in the course design process. Another important feature included in the tool is a graphical assistant (wizard), which guides instructors through the needed steps to create a proper instructional design. The main aim of these features is to reduce the learning curve, avoiding the resistance to change.

On the other hand, this paper presents an evaluation of our proposal tool, which is focused on getting some feedback about the usability and the value of use it in their course planning. This evaluation is applied with a System Usability Scale test (SUS) on to instructors who have worked with the ID Tool, and an eye-tracking test to instructors whose have never used it.

The rest of the paper is organized as follows; Section II provides background information required to understand the paper. Section III is about the related work. Section IV presents our proposal tool. Section V evaluates our approaches. Section VI discusses the results. Section VII, VIII and IX describes limitations, conclusions and further work respectively.

\section{Background}

Many definitions of instructional design has been proposed. A first understanding is what is meant by literal interpretation of words "design" and "instruction". In accordance with Fernández [3] design can be understood like sketch, description, definition, planning or research; and in a educational context, it facilitates an organizational structure for, among others, evaluations, topics and bibliography to be applied in learning processes. Likewise, the author mention that instruction is usually applied to a educational methods. 
Finally, the author says the instructional design, is a process of prior organization of teaching methods, also including the design and implementation of feedback mechanisms to improve the instrument generated.

The Instructional Design Central (IDC) community [4] defines the instructional design as "[...] the systematic development of instructional specifications using learning and instructional theory to ensure the quality of instruction. It is the entire process of analysis of learning needs and goals and the development of a delivery system to meet those needs. It includes development of instructional materials and activities; and tryout and evaluation of all instruction and learner activities."

This same author has another interesting definition about instructional design as a science: "Instructional design is the science of creating detailed specifications for the development, implementation, evaluation, and maintenance of situations that facilitate the learning of both large and small units of subject matter at all levels of complexity" [4].

Otherwise, Valiathan [5] defines the instructional design as process, a system and a discipline that is influenced by learning theories. And it has different perspectives: from a learning perspective "... it is a branch of knowledge concerned with translating general principles of learning into plans for instructional materials and learning" [5]. From a process perspective, it "... is a set of activities that are undertaken for designing instruction, with the goal of optimising learning experiences to achieve specific objectives" [5].

As well, Gustafson and Branch [6] mention that a instructional design is a system, but they go beyond and mention that it is integrated with a set of elements that interact with each other, and it has this characteristics:

1) Interdependent: means that all the elements in a instructional design are necessary, if any of they be deleted the instructional process would not accomplish the objective properly.

2) Synergistic: means that all elements of the instructional design are complementary to each others, to achieve a common goal, each element individually is not enough.

3) Dynamic: means that a ID is an alive system, so it can be adapted depending on the changes in the environment.

4) Cybernetic: means all the elements into the system can effective communicate, forming a network connection between them.

According to the authors, these characteristics are essential to understanding instructional design process and how its elements work together to achieve the system's goals and objectives.

Likewise, Berger \& Kam [7] indicate that the instructional design is a systematic process by which instructional materials are designed, developed and delivered. It concerns the hole process of analysis of the learning needs and objectives, and the development of a delivery system that meets those needs. This includes the develop, testing and evaluation, of instructional activities, assessments and materials.

According with Branch \& Kopcha [8], the instructional design process works best when it is matched to a corresponding context. However, they say, educational contexts are often complex. In this way, the authors argue that "... effective instructional design models need to be sensitive to different educational contexts and be responsive to complex teaching and learning situations" [8].

Moreover, many models has been proposed and evolved over the history [9]. According with the IDC, "Instructional design models help instructional designers to make sense of abstract learning theory and enable real world application. An instructional design model provides structure and meaning to an instructional design problem" [10].

Finally, a generally accepted instructional design model is the ADDIE model [8], [10]. ADDIE is an acronym for analysis, design, development, implementation, and evaluation, and the IDC mention that "these processes represent a dynamic, flexible guideline for building effective training and performance support tools" [10]. According with [11] the model adopted at TEC, follows the ADDIE model.

\section{Related Work}

This section studies some work related to ID Tools, in particular, similar tools which could help solve the presented problem. This search has identified different kinds of tools, most of them are based on ID models, such as ADDIE [10]. Some of them, are more oriented to create learning contents or learning object, known as authoring tool. In particular, the tools found with more relevance regarding our requirements are:

1) LAMS (Learning Activity Management System) [12]. This tool focuses on the design, management and presentation of online collaborative learning activities. Its graphical user interface (GUI) is based on icons, giving the instructor an easy way to track the learning process like a flow of activities. This tool has the facility to add learning objects, discussions and votes between students. It can also integrate its learning activities with collaborative tools such as wikis and forums. This GUI is very appropriate to be used at schools and high schools.

2) Phoebe [13]. This is a tool to support ID, it has a template set to add information about courses and their context , including students, learning activities flow, curricular things and others. This tool is more focused on the learning object planning than the whole course.

3) Nugget Developer Guidance [14]. This application provides a tool box for object learning planning, tool search and resources for the course. This tool permits resources (nuggets) reuse.

4) LCDS (Learning Content Design System) [15]: Microsoft tool to develop online courses resources. These resources include learning activities and auto 
evaluation. But not includes an ID creation for whole courses.

Furthermore, tools included on review web sites such as EduTools were also studied [16]. All the this tools have interesting features, but most of them are focused on the creation of learning objects instead of the course planning. On the other hand, these tools do not have a full integration with an LMS, where our solution requires to be fully integrated with .LRN. In the next section, the ID Tool will be described.

\section{ID Tool}

In this section will be described the instructional design tool developed by TEC Digital. This group is the e-learning instance at Tecnológico de Costa Rica, as a part of a set of advanced services to students and teachers [17].

In the follow subsections there is a description of how the ID tool was designed and developed.

\subsection{ID Tool Architecture}

One important step before starting with the design of the architecture is to get a good understanding of the system requirements. The functional requirements of ID Tool are strongly based on this objective and they will be more clearly illustrated in the ID tool GUI section. Regarding the non functional requirements, the most important is that the tool should be based on the .LRN platform, which is the e-learning core used at TEC.

Furthermore, one very important feature is flexibility at development level, so that the tool can be extended and integrated with other components of TEC Digital. Other non-functional requirements such as security, authentication, simultaneous connections and others, are provided by the platform.

Based on these general requirements, the architecture design of ID Tool is basically a three levels architecture following a Model View Controller (MVC) pattern:

1) Model layer: This layer is related with the data base, includes the data related with the tool and the data collected from the users. One important aspect of this design is that the components of the ID have their own table, allowing to do a transversely searches and to add or remove components of this matrix in an easier way than if all were in the same table. The data base engine is based on PostgreSQL 8.4 .

2) Controller layer: this layer contains the business logic, and the communications between the Model layer and View layer. Furthermore, this layer supports the integration with another tool named Course Syllabus Manager, which manages the courses syllabus. The course syllabus tool has a template which are the guide of the courses and on which the ID is based. This layer was developed under the openACS-dotLRN platforms, specifically on the TCL (Tool Command Language) programming language.

3) View layer: finally, the view layer manages all aspects regarding GUI. The main goal of this layer is to offer more natural, intuitive and easier-to-use interfaces to instructors. This layer was developed with the programming languages ADP (AOL Dynamic Pages), JavaScript, jQuery and CSS.

\subsection{ID Tool Graphical User Interface}

ID tool was designed by an interdisciplinary team formed by designers, pedagogical advisors and software engineers. This strategy was very important to achieve the final GUI.

Each member of the team had a specific part to contribute: the designers were the responsible for defining the colors, icons, position of the information and the most important aspect, the usability of the application. This was the most complicated aspect about the tool, because the instructors should be able to create an ID without many knowledge about the ID nor the tool. They should regard the ID tool as a natural and intuitive pedagogical tool to improve the planning of their courses, not like extra work to do.

The pedagogical advisors had the responsibility to assure the completeness of the features or components needed to guide the instructors on the right way. Their contributions include: the ID components required to achieve a complete planning flow; the short guides texts, which guide the instructor everywhere; the complete help text to assist the instructors if they want more information about the ID creation process and the steps necessaries to get a good courses planning. Finally, the software engineers worked to find out the technology necessary to implement this design and the development of it.

So, according with the ID tool flow, the first step after user log-on to the tool, is to select the course for which you want to create an ID. Then, the course syllabus and its template are shown. This information is important for the teacher in order to know some details that will be required for the ID creation.

The course syllabus and template have the information related with the course basics. These information are:

1) Information about the course like: the university name, the career and the course name. Then, the courses that are prerequisite for this course, the hours required per week, the kind of course (virtual or classroom) and other things more specific about TEC.

2) The description of the course, related with the main goals, the specific goals, the course contents, the methodology to be followed, suggested evaluation, recommended bibliography and general comments for this course.

Once the instructors read and get involved with the course template, the context part is coming next. This part 
is recommended by the pedagogical advisors, because the instructors making this kind of exercise get extra knowledge that will be very useful to improve their strategy at the moment of the ID creation.

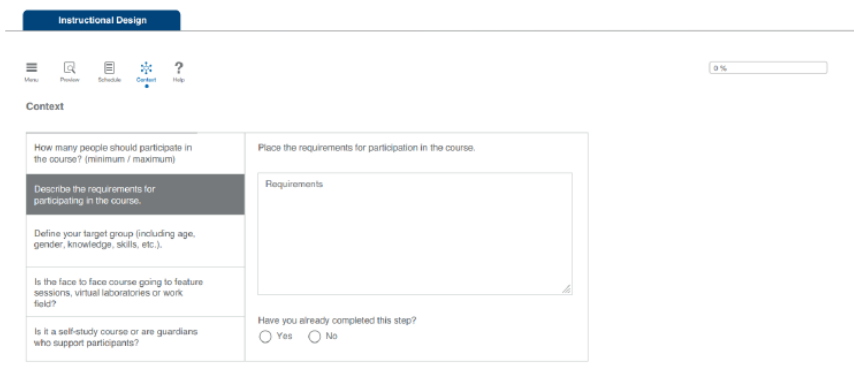

Figure 1. Course Context.

As seen on Figure 1, the context is a list of questions about the things related with any course, as number of students, which are the course pre-requisites, students information (age, gender, skills, others) and others customizable questions. The tool allows to save these answers and the state of the process at a given point; for example, if the instructor cannot finish a question for any reason, the instructor can mark this question as unfinished and the tool will keep track of that. It is important to mention, that this context part is optional; if the instructor knows very well the course, he/she could skip this step.

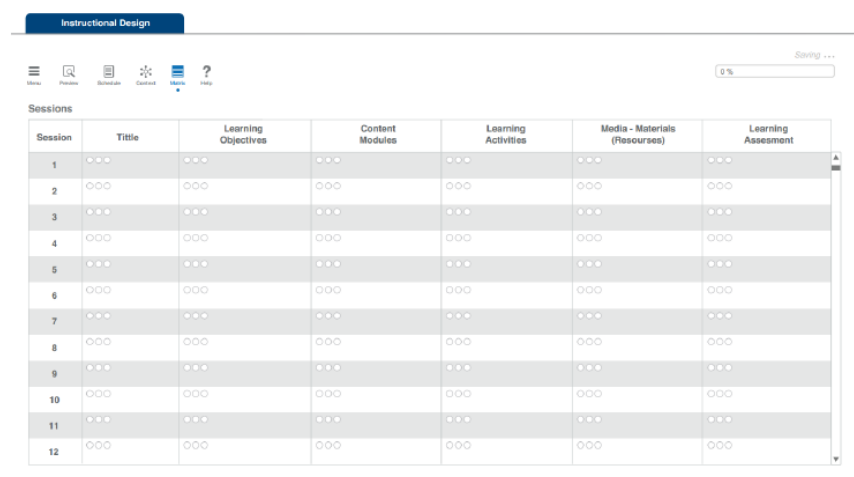

Figure 2. Instructional Design Matrix.

Figure 2 shows the progress bar and at the middle the content's container, in this case the ID matrix. From the main icon menu at the top-left of this figure, the available actions are:

1) Options to open, new, save, save as and exit.

2) Preview: this option allows to download the ID in CSV format; it could be opened to see the whole ID, to print it, to share it with the students or other instructors.
3) The course syllabus: it's a shortcut to basic information, it's very useful for the instructors in order to create their ID.

4) The context: it has the same course templates function, but displaying the context section.

5) The Matrix, it is use to come back to the table if the instructor is looking the context or the syllabus. This is the default option.

6) Help, contains the whole help about the tool and the ID creation process.

Finally, the last four options change the content container, that means when the instructors choose any of this options, the content of the screen will change making a transition effect. This was designed in this way to keep the instructors on the same page, avoiding distractions opening more tabs or pages.

Then, to the right of the main menu, there is a progress bar, which shows instructors the current percent of finished work on this ID. As it will be described later, each component of this Matrix has a state, so the progress bar will be displaying the progress of finished components.

Another important feature is the label above the progress bar, "saving..." this is to indicate the ID is being saved on this moment. This feature works once the instructors have saved the ID for the first time; auto-saving works each two minutes.

Continuing with the ID Matrix or the work area, it has seven columns, which represent the specific components of the ID. These components will be planed for each session by the instructor. The rows represents the sessions of the course that will be given. The total sessions were given by the instructor when he/she selected the course.

The table components were analyzed by the pedagogical advisors and they conform with the ID model used by TEC. These components have a specific goals, namely:

1) Tittle: descriptive name to the current session, it is used to classify or name this session.

2) Learning goals: its main meaning is to specify the goals that will be achieved by the student, for example "To know the principal characteristics of a relational data base".

3) Content Modules: this component specifics the topics to be covered in this session, the modules, units, and others. In this case, this component should be filled out based on the course template since it has the recommended units.

4) Learning activities: this component includes the plan of all activities that need to be followed to help the student to achieve the learning goals. This is the list of step-by-step activities on this session, e.g. work in groups, speech, others.

5) Means and materials: this column lists the materials or means that will be used to support the learning goals, for example videos, tours, others.

6) Learning assessment: here, the instructor will write the plan about how to evaluate if the learning goals are achieved or not. This is very important, because 
the instructor could measure the students level in different ways. For example: test, quiz, discussion panel, others.

On the other hand, inside any table cell there are three circles, which means the state of the cell specification. The states are:

1) Three green circles: this cell is finished.

2) Two orange circles: the content of the cell is in progress, but it isn't finished yet.

3) One red circle: it means that the instructor has not worked on this cell yet, but is working in this session.

4) Three empty circles: The instructor has not worked here yet.

On this table the instructors will have a clean work area, because they only will have circles with the progress of the ID creation. If the table had all the information displayed at the same time, it will be very difficult to to find and to edit the information.

The big challenge at this point of the ID specification process is, how the instructors add the information avoiding the monotony of filling out many cells. To tackle this challenge, this tool includes a wizard to make the creation process more guided and interactive for instructors.

As seen on Figure 3, when the instructors click one cell, a wizard pops up. The main sections of this wizard are:

1) Heading: it has the information about which cell the instructor is working on at that moment; here, the session number and the component name are displayed. Additionally, there are two rows to navigate over the components of this session.

2) Left panel: here are all the ID components are displayed; the current component is indicated with a different background color. Clicking on any of these components, the instructor can select the next component to be edited.

3) Right panel: this is the section where the instructors edit or add the ID component information. This section includes: the Add button, to add another text field to include more information; the quick guide, to indicate the purpose of this component to the instructor; the text field to add the information(next to it there is an $\mathrm{X}$ and a Check, to erase the text or confirm it).

Furthermore, the usability is important too: the instructors have the help, context and course syllabus within just one click from their work area, and can go back in the same way. Another advantage is the auto-saving, mentioned before, and also the instructors can make versions of their ID.

As it was explained in previous sections, this tool could be a strategic instrument to the instructors in the way they design their courses, but this tool would be more important yet, if it integrated with several e-learning platform components besides the base .LRN LMS. Most of these components have been developed specifically for TEC Digital.

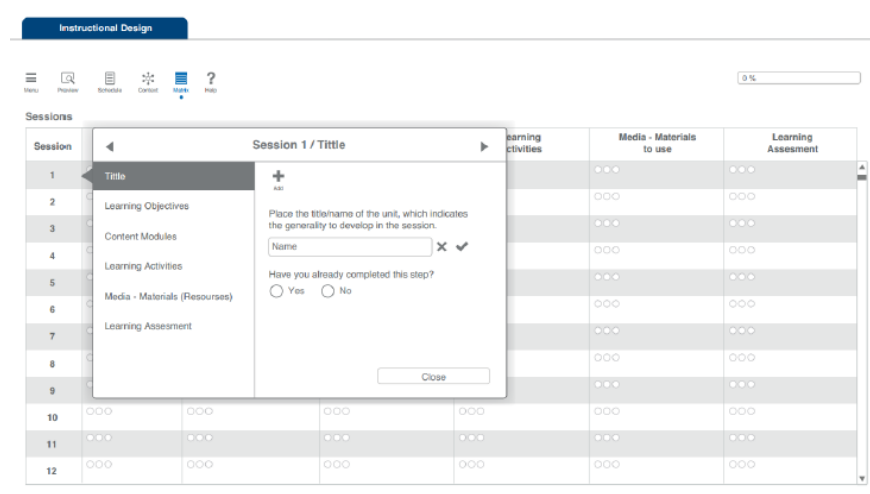

Figure 3. Tools wizard.

This integration plan will be explained in the next section as future work.

\section{Usability analysis of the ID Tool}

To analyze the usability of the proposal, have been designed two studies: a questionnaire based on the System Usability Scale (SUS) [18], and an eye-tracking test. The desired goal using these tests is to diagnose an initial usability level in the ID tool. The first subsection presents the SUS approach followed and the results of its application. The second one, presents the eye-tracking [19] test was done and the results obtained.

\subsection{System Usability Scale}

According to Brook [18], the usability of any system depends or is appropriate to its context. The context is understood as the environment and people that uses the system. As the results found in [20], the SUS approach was selected to get the instructors opinion about the usability of the ID tool, following the next criteria: (1) simplicity of the questionnaire, (2) wide usage among the industry, (3) reliable across small sample sizes, (4) the questions in the SUS, address different aspects of the user's reaction, using all the elements into the web system, and (5) the SUS have been tested for more than twenty five years in usability studies around the globe [21].

The SUS is a usability scale based on a likert scale. The user answer ten-item questionnaire, indicating the degree of agreement or disagreement on a five point scale [18]. The author of SUS, propose a mechanisms to score the test applied, and is as follows:

"To calculate the SUS score, first sum the score contributions from each item. Each item's score contribution will range from 0 to 4 . For items 1 , $3,5,7$, and 9 the score contribution is the scale position minus 1. For items 2, 4, 6, 8 and 10, the contribution is 5 minus the scale position. Multiply the sum of the scores by 2.5 to obtain the overall value of $S U$ ” [18]. 


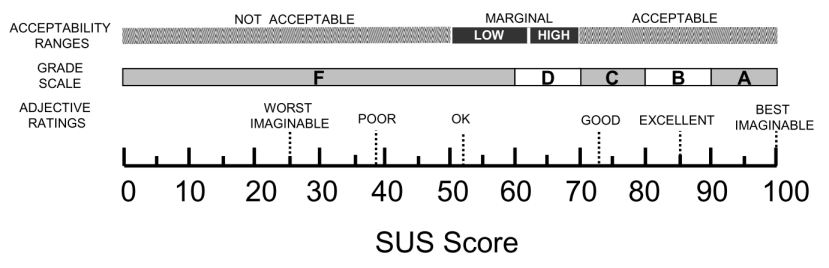

Figure 4. A comparison of the adjective ratings, acceptability scores, and school grading scales, in relation to the average SUS score from "Determining What Individual SUS Scores Mean: Adding an Adjective Rating Scale," by A. Bangor, P.T. Kortum, and J.T. Miller, 2009, Journal of Usability Studies, 4(3), 114-123. [22]

According to Sauro [23], 68 is the average score. The author says the systems under this score have some usability issues, that they have to be studied and fixed. Indeed, another authors [22] mention a grade scale and acceptability ranges related to the SUS score. The grade scale refers a letter grade scale could be an alternative to understand the meaning of SUS. The acceptability range is a help to determine if a given SUS score indicated an acceptable interface or not. This relationship between the ranges can be seen in the Figure 4.

TABLE 1. SUS APPLICATION RESULTS

\begin{tabular}{|c|l|l|l|l|}
\hline$\#$ & Question & Minus 3 & Exact 3 & Plus 3 \\
\hline 1 & $\begin{array}{l}\text { I think that I would like } \\
\text { to use this system fre- } \\
\text { quently. }\end{array}$ & $5.40 \%$ & $13.52 \%$ & $81.08 \%$ \\
\hline 2 & $\begin{array}{l}\text { I found the system un- } \\
\text { necessarily complex. }\end{array}$ & $27.02 \%$ & $45.96 \%$ & $27.02 \%$ \\
\hline 3 & $\begin{array}{l}\text { I thought the system was } \\
\text { easy to use. }\end{array}$ & $40.54 \%$ & $8.11 \%$ & $51.35 \%$ \\
\hline 4 & $\begin{array}{l}\text { I think that I would need } \\
\text { the support of a techni- } \\
\text { cal person to be able to } \\
\text { use this system. }\end{array}$ & $27.02 \%$ & $10.82 \%$ & $62.16 \%$ \\
\hline 5 & $\begin{array}{l}\text { I found the various func- } \\
\text { tions in this system were } \\
\text { well integrated. }\end{array}$ & $24.32 \%$ & $32.44 \%$ & $43.24 \%$ \\
\hline 6 & $\begin{array}{l}\text { I thought there was too } \\
\text { much inconsistency in } \\
\text { this system. }\end{array}$ & $40.54 \%$ & $37.84 \%$ & $21.62 \%$ \\
\hline 7 & $\begin{array}{l}\text { I would imagine that } \\
\text { most people would learn } \\
\text { to use this system very } \\
\text { quickly. }\end{array}$ & $24.32 \%$ & $24.33 \%$ & $51.35 \%$ \\
\hline 8 & $\begin{array}{l}\text { I found the system very } \\
\text { cumbersome to use. }\end{array}$ & $54.05 \%$ & $27.04 \%$ & $18.91 \%$ \\
\hline 9 & $\begin{array}{l}\text { I felt very confident us- } \\
\text { ing the system. }\end{array}$ & $16.21 \%$ & $29.74 \%$ & $54.05 \%$ \\
\hline 10 & $\begin{array}{l}\text { I needed to learn a lot of } \\
\text { things before I could get } \\
\text { going with this system. }\end{array}$ & $21.62 \%$ & 29.74 & $48.64 \%$ \\
\hline
\end{tabular}

The sample used to make this test are instructors at TEC which had some experience using the ID Tool. The test, also include questions about gender, teaching experience, age and a open question. The objective with this last question is to get some relevant opinions of the instructors. The test was send to around one hundred and seven instructors ${ }^{1}$, and thirty-eight instructors have replied. Based on the demographics of the instrument applied, there is a balance between the respondents in terms of age (Range: 21-65 years), gender (Male $=49 \%$ and Female $=51 \%$ ), and years of experience teaching (Range: 6 months to plus 10 years). The results obtained are shown in the Table 1 . The SUS score given to the ID Tool is 56.92, consequently the grade scale obtained is a F and the acceptability range is marginal.

\subsection{Eye-tracking test}

According to [19] the eye-tracking tool performs two jobs: first, to record eye movements which represents the "path" followed. While these movements are recorded, the other job detects the changes in the pupil. After tracking the path followed by the eye and determine the focus points, the eye-tracking system records the scene (image projected on the computer's screen) and performs the appropriate analysis, providing information on the route followed eyes, focus points and a representation of the time period used. The eye-tracking tool used a heat map and a gaze plot to express the results, an example is shown below.

In this case, the eye-tracking analysis have been applied to six instructors, that according with [24] five users would be good enough sample. The profile defined to make the tests are instructors without previous experience using the ID Tool. The instructors must perform two tasks, with some steps on each of them. This tasks are:

1) ID Creation: The instructors had to access the ID Tool, create an ID, add three sections and complete the session one. An example of the result is seen in the Figure 5 by a heat map.

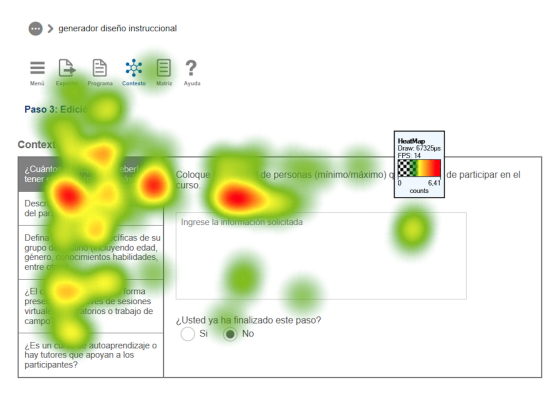

Figure 5. Heat Map of the context when a user is creating a new ID

2) ID Interaction: The instructors had to modify the session one and associate the ID to a course. The Figure 6 shows an example of the interaction with the wizard when a user is changing a session by a gaze plot.

1. The questionnaire applied can be accessed in the link: https://goo.gl/ 53H4FR 


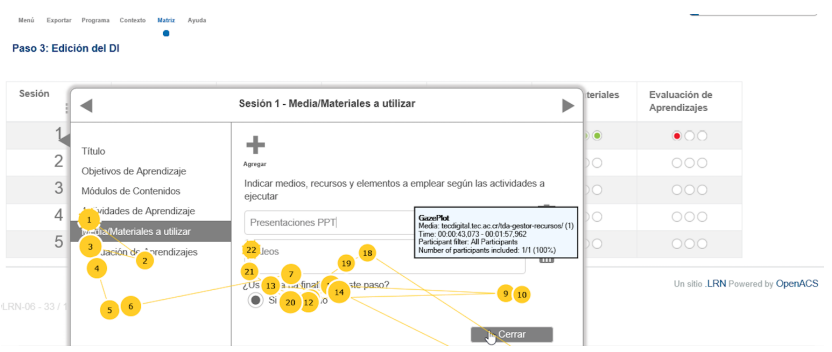

Figure 6. Gaze Plot of the wizard window when a user is changing the elements of a session.

With those tasks, it is possible to detect if the graphical user interface design is according with the users expectations and evaluate the tools' usability. The results of this test are shown in the Table 2.

TABLE 2. EYE-TRACKING TEST RESULTS

\begin{tabular}{|c|c|c|}
\hline \multirow{2}{*}{ Evaluated item } & \multicolumn{2}{|c|}{ Total of users } \\
\hline & Task 1 & Task 2 \\
\hline Task done in 2 minutes or less & 5 & 6 \\
\hline $\begin{array}{l}\text { Correct placement of elements in } \\
\text { the graphical interface }\end{array}$ & 4 & 6 \\
\hline $\begin{array}{l}\text { Understanding of the interface la- } \\
\text { bels }\end{array}$ & 6 & 6 \\
\hline
\end{tabular}

The Table 2, shows a brief of the principal results evaluated in the eye-tracking test and the number of users that achieve the task.

Something very important to be mentioned is the process to be followed to do an eye-tracking test. It must begin with the describing the task to the instructor, then, take notes about the how the instructor does it. During the test, is very important do not talk with the user, neither to answer questions about the tool, because the main goal is to simulate the most real user experience as possible. Who execute the test is know as Test Manager.

\section{Discussion}

This section discusses and analyses the results obtained in the SUS and eye-tracking tests, in terms of the degree of easy of use the ID Tool. The first subsection presents the results related to the questionnaire applied. The second subsection presents the discussion about the results related to the eye-tracking test.

\subsection{SUS results}

The SUS application return interesting results. The first impression is that the ID Tool have usability issues, and some elements need a redesign to improve the user experience, and so on, improve the SUS score. In detail, there are important considerations to mention.

Following the results in Table 1 , the $81 \%$ of users agree that the ID Tool is necessary in their environment, and they would like to use it frequently. As a result, we can conclude that the idea of a instructional design helper as a part of an LMS is widely accepted and necessary.

It is not clear if the system is complex or hard to use. This because the around $46 \%$ of the users have a neutral position in this question. Most compelling evidence, is that there are the same quantity of the users which agree (27\%) and disagree $(27 \%)$ in terms of the system use complexity. Equally, the most quantity of users (51\%) agrees that the system is easy to use, but a considerable quantity $(40.5 \%)$ disagrees that it is difficult to use. But, the most users $(62 \%)$ agree that they need support to use the system, a assumption can be made: the system has some initial complexity to use.

Another interesting result, is derived by the analysis of the items eight and nine. The most of the users $(54,05 \%)$ feel confident using the ID Tool, and they think the system is not much "cumbersome".

The inclusion of a text input for users' open opinions about the ID Tool using experience into the SUS questionnaire, returns positive feedback in order to improve the user experience. For example, a user said "the user interface is complex, I have tried to use by my own, but It was difficult to use it in first instance, I have to take training to learn use it". Another opinion was "more than a difficulty using tool, I think the hard part is the conceptualization of a course planning; this is not a widely known concept by all the instructors in the institution".

Finally, the results obtained by the application of the SUS show a quick and general evaluation of the general usability, in terms of the users' perspective. Along the same line, the ID Tool SUS grade tool shows that there are elements to be improved. However, the ID tool is well accepted in accordance with the users' opinions. But, what specific issues has to be covered to improve the user experience of the ID Tool? To know that with certainty, more specific studies has to be carry out but some possible lines are improve the auto-learning mechanisms and improve some visual elements that can affecting the user understanding of the system.

\subsection{Eye-tracking results}

For more specific information on usability elements that can be affecting the usability of the GDI, eye-tracking tests have been designed and implemented, and the results can be seen in the Section 5.2.

The use of the eye-tracking test was very useful, inasmuch as the SUS test shown some improvement points, that cant be addressed to a specific task, action or an element in the GUI, so, the eye-tracking was very important to clarify this issues.

During the test, the following issues was discovered:

1) Tasks' duration: each tasks had some steps to be follow to complete it, so the max duration of this two tasks were defined both in two minutes. In the first one, just one instructor could not finished on time. In the test manager's notes were described 
that some graphical elements in the context phase affected the users' concentration. This elements was located easily using the gaze plot.

2) Placement of the GUI elements: An important thing in the GUI is the correct placement of its elements, in this case were found that the matrix does not seems to be clickable for two instructors, this was written by the task manager and checked by the gaze plot, where is shown how the user looked in some places trying to find how to edit the matrix.

3) Interface labels: Another important thing to evaluate are the labels, because if it are unknown by the instructor, the use of the tool will be annoying. In this case the test shown that the labels are well used, the task manager did not find issues and it was checked by a heat map.

4) Other observations: During the task, the test manager noted some ignorance about the ID theories. Related this observations with some comments in the SUS, can be concluded that is necessary some training about what instructional design is, to achieve a better results with the tool.

\section{Limitations}

This work has the following limitations to being taken in account:

1) The use of the eye-tracking tools (software and hardware) had a limited time to be used on this work, so it only had a one day to do the test. In the other hand, the instructors had to take their personal time and modify their schedule to be able to assist this specific day.

2) Moreover, the SUS test only had been used in English, for this work it was translated to Spanish to be used at Tecnológico de Costa Rica, the translation was done trying to be as exact the english version as possible.

\section{Conclusions}

Regarding the development process of ID Tool, it is important to emphasize the interdisciplinary team which worked on it. In this case, the ID tool has a user-friendly interface designed by usability experts which complies with all steps and requirements given by a pedagogical advisor. Instructors can then create IDs in less time since they can access all important information with just one or few clicks.

Furthermore, the ID matrix is designed to keep the work space as clean as possible. In the same way, through the auto-saving feature, instructors just need to focus on the ID creation, not on saving at every moment they can.

On the other hand, the future integration of ID Tool with other TEC Digital modules, is considered very important in order to offer the instructors an integrated LMS, where they can do many things following a natural steps from a single LMS entry point. If the e-learning platform provides an integrated service for most instructors needs, they will feel more comfortable to use it. In this way, it is expected that instructors would get more involved with the e-learning environment, more materials and virtual courses will be created, reducing the learning gap, allowing more people the access to the learning by the use of technology. Because of this, is very important to provide user-friendly tools to the instructors, which can engage them to use an e-learning solutions.

\section{Future Work}

Our next step regarding work is to improve the design of the interface, making it as usable as expected before the validation.

Firstly, it is necessary to enhance the users' auto learning methods by adding step-by-step guides and a tutorial section. Step-by-step guides can show how the user can use the system the first time he or she use it. And a tutorial section can show information about the use of the tool and information about the instructional design model followed at TEC.

It is important to improve graphical elements to make the system more understandable to the users. The tests applied shows some issues with the actual user interface elements like the option to open the wizard in the matrix section, in this way it is necessary to make a deep analysis to identify the specific elements to be improved in order to build a better usable ID Tool. Complementary, it is imperative to analyze the whole system's labels, in order to develop effective ways to show the instructions. The objective is to reduce the time used by instructors reading these components and by consequence reduce the system's time use.

Once this is done, improving and offering more training about the ID Tool and instructional design theories (and expressly in the model adopted by TEC) to the final users is a must.

Another important future work is to add more functions to the ID Tool, for example the possibility to create the entire course automatically using ID Tool, fully integrated with the LMS and its tools (including evaluations, forums, chats, news, tabs to add any kind of content, videos, images, among others); and integrates the Activities Manager Tool [25], which is a tool developed at TEC Digital in order to create learning activities such as games. This integration scenario would allow to plan games as learning activities from ID tool, and associate it with a game created with the Activities Manager Tool.

\section{References}

[1] W. Delgado, "Encuesta sobre Diseño Instruccional," Cartago, Costa Rica, 2011.

[2] T. Moreira-Mora and J. Espinoza-Guzmán, "Initial evidence to validate an instructional design-derived evaluation scale in higher education programs," International Journal of Educational Technology in Higher Education, vol. 13, no. 1, p. 11, 2016. [Online]. Available: http://www.educationaltechnologyjournal. springeropen.com/content/13/1/11 
[3] N. Fernández, "Factores psicopedagógicos de influencia en la eficiencia terminal de actos académicos de educación continua por internet," Master's thesis, Universidad Nacional Autónoma de México, Mexico, 2004.

[4] Instructional Design Central, "What is Instructional Design?" p. 5, 2012. [Online]. Available: http://www.instructionaldesigncentral.com/ $\mathrm{htm} /$ IDC_aboutinstructionaldesigncentral.htm

[5] P. Valiathan, "Instructional design," Training Journal, p. 74, 01 2010, copyright - Copyright Fenman Limited Jan 2010; Última actualización - 2016-03-05; SubjectsTermNotLitGenreText - United Kingdom-UK. [Online]. Available: http://search.proquest. com/docview/202958338? accountid=14609

[6] K. L. Gustafson and R. M. Branch, "What Is Instructional Design?" in Trends and issues in instructional design and technology, 2002, pp. 16-25. [Online]. Available: http://jan.ucc.nau.edu/ etc-c/etc667/ 2006/readings/gustafson1a.pdf

[7] C. Berger and R. Kam, "Adapted from "Training and Instructional Design”, Applied Research Laboratory, Penn State University," 1996. [Online]. Available: http://www.umich.edu/ ed626/define.html

[8] R. M. Branch and T. J. Kopcha, Instructional Design Models. New York, NY: Springer New York, 2014, ch. Instructio, pp. 77-87. [Online]. Available: http://link.springer.com/10.1007/ 978-1-4614-3185-5

[9] A. S. Gibbons, E. Boling, and K. M. Smith, Instructional Design Models. New York, NY: Springer New York, 2014, ch. Section VI, pp. 607-615. [Online]. Available: http://link.springer.com/10.1007/ 978-1-4614-3185-5_48

[10] Instructional Design Central, "Instructional design models and methods," 2012. line]. Available: http://www.instructionaldesigncentral.com/htm/IDC_ instructionaldesignmodels.htm

[11] W. Montoya-Delgado, “"Lineamientos curriculares para la formación académica en entornos virtuales en el Instituto Tecnológico de Costa Rica.,", 2012. [Online]. Available: http://www.tec.ac.cr/eltec/reglamentos/Documents/ Lineamientos\%20curriculares\%20propuestos\%20EVA_2013.pdf

[12] J. Dalziel, "LAMS TM - Learning Activity Management System," 2003. [Online]. Available: https://www.lamsinternational.com/

[13] D. Balch, M. Manton, and L. Masterman, "Phoebe: pedagogic planner," p. n.p., 2012. [Online]. Available: http://www.phoebe.ox. ac.uk/

[14] D. K. Schneider, "DialogPlus Toolkit - EduTech Wiki," 2014. [Online]. Available: http://edutechwiki.unige.ch/en/DialogPlus_Toolkit

[15] Microsoft, "Create online courses and Silverlight Learning Snacks with LCDS." [Online]. Available: https://www.microsoft. com/learning/en-us/lcds-tool.aspx

[16] S. Leslie, "Important Characteristics of Course Management Systems: Findings from the Edutools.info project," 2003. [Online]. Available: http://www.edtechpost.ca/gems/cms_characteristics.htm

[17] M. Chacon-Rivas and C. Garita, "A Successful OSS Adaptation and Integration in an e-Learning Platform: TEC Digital," in Open Source Software: Mobile Open Source Technologies, 2014, vol. 427, pp. 143-146. [Online]. Available: http://link.springer.com/10.1007/ 978-3-642-55128-4_19

[18] Brooke J., "SUS-A quick and dirty usability scale," Usability evaluation in industry, pp. 4-7, 1996.

[19] Tobii, "Tobii Eye Tracking - An introduction to eye tracking and Tobii Eye Trackers," Technology, p. 12, 2010. [Online]. Available: http://acuity-ets.com/downloads/Tobii\%20Eye\% 20Tracking\%20Introduction\%20Whitepaper.pdf

[20] T. S. Tullis and J. N. Stetson, "A Comparison of Questionnaires for Assessing Website Usability ABSTRACT : Introduction," Usability Professional Association Conference, pp. 1-12, 2004. [Online]. Available: http://home.comcast.net/ tomtullis/publications/ UPA2004TullisStetson.pdf
[21] J. Brooke, "SUS : A Retrospective," Journal of Usability Studies, vol. 8, no. 2, pp. 29-40, 2013. [Online]. Available: http://uxpajournal.org/sus-a-retrospective/

[22] A. Bangor, P. Kortum, and J. Miller, "Determining what individual SUS scores mean: Adding an adjective rating scale," Journal of usability studies, vol. 4, no. 3, pp. 114-123, 2009. [Online]. Available: http://66.39.39.113/upa_publications/jus/ 2009may/JUS_Bangor_May2009.pdf

[23] Jeff Sauro, "Measuring Usability With The System Usability Scale (SUS)," 2011. [Online]. Available: http://www.measuringu.com/sus. php

[24] N. Bevan, C. Barnum, G. Cockton, J. Nielsen, J. Spool, and D. Wixon, "The "magic number 5": Is It Enough for Web Testing?" CHI '03 extended abstracts on Human factors in computing systems - CHI '03, no. 5, p. 698, 2003. [Online]. Available: http://portal.acm.org/citation.cfm?doid=765891.765936

[25] I. Mora, M. Fallas, C. Garita, and M. Chacón, "A Learning Activities Management Tool for English Teaching," in Third Costa Rican Conference of Teachers of English: A Challenging Tool: Using Eteaching to engage students within a digital world., Cartago, Costa Rica, 2012. 